\title{
Societal Burden of Clinically Anxious Youth Referred for Treatment: A Cost-of-illness Study
}

\author{
Denise H. M. Bodden • Carmen D. Dirksen • Susan M. Bögels
}

Published online: 23 January 2008

(C) The Author(s) 2007

\begin{abstract}
A prevalence-based cost-of-illness study using a societal perspective was conducted to investigate the costof-illness in clinically anxious youth aged 8-18 in The Netherlands. Discriminant validity of the cost diary used was obtained by comparing costs of families with an anxious child $(n=118)$ to costs of families from the general population $(n=41)$. To examine the convergent validity, bottom-up acquired costs derived from cost diaries were compared to top-down acquired costs obtained from national registrations. Bottom-up acquired costs measured by means of cost diaries amounted to $€ 2,748$ per family of a clinically referred anxious child per annum. Societal costs of families with clinically anxious children were almost 21 times as high compared to families from the general population. With respect to convergent validity, total health care costs using the bottom-up approach from clinically anxious children were quite comparable to those of top-down data of anxious children, although costs within the subcategories differed considerably. Clinical anxiety disorders in childhood cost the Dutch society more than 20 million euros a year. Based on results of discriminate and convergent
\end{abstract}

D. H. M. Bodden $(\bowtie)$

Research Centre of Psychosocial Development in Context, University of Utrecht,

P.O. Box 80140, Utrecht 3508 TC, The Netherlands

e-mail: D.Bodden@uu.nl

C. D. Dirksen

Department of Clinical Epidemiology and Medical Technology

Assessment, University Hospital Maastricht,

P.O. Box 5800, Maastricht 6202 AZ, The Netherlands

S. M. Bögels

Department of Education, University of Amsterdam,

P.O. Box 94208, Amsterdam 1090 GE, The Netherlands validity, the cost diary seems a valid method in establishing cost-of-illness in childhood anxiety disorders.

Keywords Anxiety disorders · Cost-of-illness .

Children $\cdot$ Cost diary

Anxiety disorders are among the most common childhood mental disorders. Prevalence rates for children with anxiety disorders vary considerably in the international literature from 1.8 (Anderson et al. 1987) to 25\% (Kessler et al. 1994). In The Netherlands, a 6-month prevalence rate of $23.5 \%$ for anxiety disorders was found in 13 - to 18 -year-old adolescents. When impairment in daily functioning is taken into consideration, Klein and Pine (2002) estimated the prevalence rate to be between 5 and $10 \%$. A Dutch study revealed that the prevalence rate of severely interfering child anxiety disorders is $9.7 \%$ (Verhulst et al. 1997). The yearly prevalence rate of children with a mental disorder seeking treatment in mental health care ranges from 1.6 (Sytema and Koopmans 1998) to 8.1\% (Leaf et al. 1996). In The Netherlands, merely $3.5 \%$ of 4 - to 18 -year-old children with a mental disorder had been referred yearly to mental health care for treatment (Verhulst and van der Ende 1997). This latter percentage resembles the $4 \%$ of Dutch people with anxiety disorders who are referred for further treatment by their general practitioner (van Wieren et al. 2007).

With respect to costs, the total costs for anxiety disorders in adults were highest of all mental illnesses, namely 46.6 billion dollars, accounting for $31.5 \%$ of total expenditures for mental health in 1990 in the USA (Dupont et al. 1996). Greenberg and colleagues (1999) estimated the annual costs of anxiety disorders in adults to be 63.1 billion dollars in the USA in 1998 by extrapolating the costs of 1990. Besides direct costs of treating anxiety disorders, indirect costs due to impaired social functioning, such as 
financial dependence and unemployment also are found in adults with anxiety disorders (Leon et al. 1995). In The Netherlands, health care costs of anxiety disorders across all ages were 180 million euro in 1999, accounting for $0.5 \%$ of the health care budget. More specifically, health care costs due to anxiety disorders in 1- to 24-year-old children and young adults amounted to 21.6 million euros (Polder et al. 2002).

An analysis to measure the magnitude of costs related to illness is called a cost-of-illness study and involves an estimation of the total economic burden which an illness imposes on society. The main objective of a cost-of-illness study is to translate the burden on society into monetary costs. Typically in a cost-of-illness study all costs associated with a particular illness are identified and measured, including health care costs, patient and family costs and costs occurring in other sectors. The results of a costof-illness study can be used to gain insight in how much society is spending on a disease, and how much potentially can be saved if effective treatment is offered. Also, it identifies the different cost categories and the size of the contribution of each sector in society. The information coming from cost-of-illness studies can be helpful in setting priorities for health care efficiency research (Ament and Evers 1993; Polder et al. 2002; Rice and Miller 1995).

Essentially there are two approaches to establish the cost-of-illness, namely the bottom-up and the top-down approach. The bottom-up approach acquires data on the patient level by means of registrations or self-report measures. Self-report measures contain retrospective cost questionnaires, retrospective cost interviews or prospective cost diaries (Bruijnzeels et al. 1998a; Sleed et al. 2005). The bottom-up approach enables one to capture resource use that is likely to vary from patient to patient and may not be easily extracted from existing data sources. Multiplying the costs per patient by the national prevalence rate results in the total cost-of-illness for a particular patient group. An advantage of the bottom-up approach is that detailed data can be obtained regarding costs outside the health care sector, such as costs due to productivity losses, out-of-pocket costs, costs of informal care, and costs due to absence from school. A disadvantage of this method may be that the sample of patients used for the cost-of-illness calculations is not representative of the entire patient group, for example due to strict inclusion and exclusion criteria (Oostenbrink et al. 2004; Polder et al. 2002). The top-down approach involves gathering data from existing (national) registrations on total costs of a service category such as hospital care, and dividing these costs by an appropriate unit, such as a patient group using the service category, mostly per year if appropriate. While there are benefits using this approach such as being less resource intensive, this calculation may also prove to be less accurate (Byford et al.
2003). Furthermore, when using a top-down approach it is difficult, if not impossible, to obtain costs outside the health care sector (Oostenbrink et al. 2004; Polder et al. 2002).

Another important distinction in cost-of-illness studies is that costs can be determined from a prevalence-based or incidence-based perspective. In a prevalence-based approach, the costs of a disorder are determined for a fixed period of time, as a result of the prevalence of the disorder (number of cases of a disorder at a specific time). This period is called the base period and most often studies investigate the annual economic burden, thus based on a year (Ament and Evers 1993; Rice and Miller 1995). A disadvantage of the prevalence-based approach is that it may be difficult to isolate potential differences in costs by stage or duration of the disorder (Greenberg et al. 1999). The incidence based approach estimates the lifetime costs of an illness from its onset, thus costs are assigned to the year in which the illness begins (Ament and Evers 1993; Rice and Miller 1995). Incidence based studies can isolate the differences in costs by stage or duration of the disease. However, a disadvantage of using this approach is that follow up research is required.

In this article, a prevalence-based cost-of-illness analysis was performed in 8- to 18-year-old children and adolescents with anxiety disorders, who were referred to treatment. The primary aim of this study was to establish the societal costs of illness in families with a clinically anxious child, using the bottom-up approach by means of a prospective cost diary. A secondary aim of this study was to investigate the discriminative validity of the prospective cost diary by comparing the costs related to anxiety, psychological, physical and other problems in families with a clinically anxious child to the same costs in families from the general population. The third aim of this study was to establish convergent validity by comparing bottom-up acquired health care costs obtained with the cost diaries of the clinically anxious children with top-down acquired health care costs of children with a primary diagnosis of anxiety disorder.

\section{Materials and Methods}

\section{Participants}

For the cost-of-illness study and the discriminative validity study, participants were clinically anxious children and adolescents from the general population, respectively. The clinically anxious group consisted of 118 families with a child referred for community mental health treatment because of anxiety, and participated in a multi-centre randomized clinical trial comparing family Cognitive Behavioural Therapy (CBT) with individual CBT (Bodden et al. 
submitted for publication). This study was conducted from March 2002 to November 2005, inclusion ended in March 2004. Inclusion criteria were (1) age $8-18$, (2) a primary anxiety disorder (except for obsessive-compulsive and posttraumatic stress disorder), (3) IQ $\geq 80$, and (4) at least one parent willing to participate. Children were excluded if suffering from (1) substance abuse, (2) current suicide attempts, (2) psychoses, (3) autism-spectrum disorders, or (4) untreated Attention Deficit Hyperactivity Disorder (ADHD). Children using medication for their anxiety were only included if dosage was kept constant during treatment and follow-up. There were 74 girls (63\%) and 44 boys (37\%), range $8-17$ years $(M=12.4, \mathrm{SD}=2.6)$. Most were Caucasian $(n=117,99 \%)$ and $53(45 \%)$ attended primary education. The remaining $65(55 \%)$ attended secondary education.

According to the compound diagnosis on the Anxiety Disorders Interview Schedule (ADIS; Silverman and Albano 1996), the mean number of diagnosis per child was $2.9(\mathrm{SD}=1.7)$, whereas the mean severity level of the primary diagnosis was $7.1(\mathrm{SD}=1.0)$. Furthermore, primary anxiety diagnoses consisted of social phobia $(n=37,31 \%)$, separation anxiety $(n=32,27 \%)$, generalized anxiety disorder $(n=21,18 \%)$, specific phobia $(n=20,17 \%)$, and panic disorder with or without agoraphobia $(n=8,7 \%)$. Of the 118 children, $94(80 \%)$ had one or more comorbid anxiety disorder(s); separation anxiety disorder $(n=20$, $17 \%)$, social phobia $(n=43,36 \%)$, specific phobia $(n=51$, $43 \%)$, panic disorder $(n=20,17 \%)$, generalized anxiety disorder $(n=42,36 \%)$, obsessive-compulsive disorder $(n=$ $5,4 \%)$, and post-traumatic stress disorder $(n=7,6 \%)$. Moreover, 29 (25\%) had comorbid dysthymic disorder or depression, 9 (8\%) ADHD, 2 (2\%) conduct disorder, and 1 (1\%) oppositional defiant disorder.

The sample from the general population consisted of a group of 41 families who were recruited via advertisements. Children of these families were comparable to children from the clinically anxious group based on gender, $\chi^{2}(1)=$ $19, p>0.1$, age, $F(1,154)=0.0, p>0.1$, and educational level, $F(1,154)=2.6, p>0.1$. There were 27 girls $(66 \%)$ and 14 boys $(34 \%)$, range $8-17$ years $(M=12.5, \mathrm{SD}=2.5)$. Most were Caucasian $(n=40,98 \%)$ and $16(39 \%)$ attended primary school. The remaining $25(61 \%)$ attended secondary education. According to the compound diagnosis on the ADIS, the prevalence of anxiety disorders in this sample was $12 \%(n=5)$ and $2.4 \%(n=1)$ for ADHD, closely resembling Dutch prevalence of anxiety disorders and ADHD, respectively $9.7 \%$ and $2.3 \%$ (Verhulst et al. 1997). The primary anxiety diagnoses consisted of social phobia $(n=1,20 \%)$ and specific phobia $(n=4,80 \%)$ with a mean severity level of $4.8(\mathrm{SD}=0.8)$. The overrepresentation of simple phobia and the relatively low severity rates of the anxiety disorders in the control group also support the "normality" of the control children.
All children and parents received and signed a written informed consent after receiving oral and written information on the study. Clinically anxious children, their siblings and parents were assessed before treatment and families from the general population were only measured once. Furthermore, all family members had to fill in a battery of questionnaires, including a prospective cost diary.

\section{Anxiety Disorders Interview Schedule}

Children's diagnostic status was assessed using the Dutch ADIS-C/P (Siebelink and Treffers 2001), which is a semistructured diagnostic interview measuring anxiety disorders and other DSM-IV childhood psychopathology. The severity score consists of impairment in daily functioning per diagnosis and ranges from 0 to 8,4 indicating a clinical diagnosis. Based on criteria, child and parents ratings are combined in a compound summary. The ADIS-C/P possesses good psychometric properties (Silverman et al. 2001). In our study, the total inter-rater agreement for all ADIS diagnoses (kappa) was averaged and was 0.89 for the ADIS$\mathrm{C}$ and 0.83 for the ADIS-P. The mean inter-rater agreement for the severity score was calculated with correlations and was 0.98 for the ADIS-C and 0.83 for the ADIS-P.

\section{Prospective Cost Diary}

A cost diary was used to determine the resources used (Freer 1980; Goossens et al. 2000) in both the costof-illness study as well as in the discriminative validity study. Cost dairies were completed prospectively by one of the parents and covered a period of 2 weeks. Families of clinically anxious children received the cost diary 2 weeks before treatment and the sample of families from the general population received the same cost diary during their one time assessment. Each cost diary was presented in a booklet form with instructions and an example diary. The cost diary was designed such that all costs which are potentially relevant to society were captured, including health care costs, patient and family costs and costs in other sectors. Parents recorded the following resource use: visits to psychologist or psychotherapist, visits to the general practitioner, outpatient consultations at the hospital, medication, day treatment, costs of paid house help, children's day care, after school care, informal care, productivity losses due to absence of work by the parents, loss of household activities or voluntary work, loss of leisure time, absence from school of the child, and out-of-pocket costs. Informal care means that persons near the family, such as relatives, friends, or neighbors, take care of the family and possibly take over some domestic tasks. Out-of-pocket costs are actual expenses made by the family (and are therefore paid 'out of the pocket'), and include for example 
transportation costs, parking costs, over-the-counter medication and own monetary contributions for health care services which are not fully reimbursed by health insurance companies. Also, parents recorded the name of the family member for whom the resource use was applicable (child, sibling, mother or father), as well as the reason for the resource use by that family member. For analysis, the reported reasons were grouped into (1) due to anxiety, (2) due to psychological problems, (3) due to physical problems, and (4) due to other reasons.

\section{Unit Prices}

Costs were calculated by multiplying the resources used, obtained with the prospective cost diaries, by the unit price of each resource. Costs were calculated at 2003 euros $(1 €=$ $0.087 \$$, July 30 th 2003). It should be noted that, whenever possible, unit prices and not transfer payments such as charges, reimbursements or patient bills were used to value health care resource use. Money transfers may bear little relation to actual resource consumption as a result of (local) budgeting agreements and political negotiations (Finkler 1982). For example, in The Netherlands hospitals receive an annual budget. As a consequence, the reimbursement of a day of hospitalization (which is the amount a hospital charges to a health care insurance company) may vary from year to year as it is used as a balancing item for a budget overdrawing. The key point is that the amount that exchanges hands between providers, third-party payers and patients are not necessarily a good measure of resources used. Therefore, for the valuation of resource consumption in health care, mostly actual unit prices are used, which are obtained by performing unit price calculations. Unit prices consist of personnel, material and capacity costs, as well as costs of housing and overhead.

Almost all unit prices were obtained by using published Dutch guideline prices (Oostenbrink et al. 2004). However, medication prices were obtained from the Medication and Aid Information Project database on the Internet (Board of Health Insurances 2005) and were based on the Daily Defined Dosage (DDD), which indicates the mean medication usage per person a day with claw back and value added tax (VAT) (20\%). An average unit price was calculated for medication for anxiety problems and medication for psychological problems. As actual unit prices for day treatment and institutionalization were not available, the prices were derived from the average of actual reimbursements (Board Tariff Rates Health Care and Care Authority 2005). It should be noted that the unit price of informal care, loss of leisure time, voluntary work and domestic activities was based on a 'shadow price' as stated in the Dutch guideline (Oostenbrink et al. 2004). A key characteristic of informal care, leisure time, voluntary work and domestic activities is that it is unpaid. So, these activities by definition do not have an official unit price, since no actual payments take place. If an official unit price is not available, resource use should be valued against a 'shadow price'. This means that informal care, loss of leisure time, voluntary work and domestic activities were valued against the wage rate per hour of a housekeeper. To determine the costs associated with absence from school, actual annual tuition, which consists of a contribution by parents and a state-subsidy per child (National Institute of Budget information 2005), was divided by the total annual hours at school according to the standard, resulting in a price per hour of school attendance. As the larger part of school costs is fixed, such as the costs of housing, (teaching) personnel and school materials, a child missing school does not result in actual savings. Therefore, the actual costs per hour of school attendance were used to value an hour of school absence. Productivity costs of the parents due to absence from paid work were calculated by means of the friction cost method, based on a mean added value of the Dutch working population (Oostenbrink et al. 2004). This method only takes into account production losses confined to the period needed (usually 90 days) to replace a sick employee.

\section{Cost-of-illness}

The primary aim of this study was to calculate the societal burden of illness of families of clinically anxious youth in The Netherlands. The cost-of-illness study was performed from a societal perspective and included direct health care costs, direct non-health care costs, indirect costs and outof-pocket costs.

The costs per family over a period of 2 weeks were extrapolated to a period of 1 year (i.e. multiplied by 26) under the assumption that data obtained with the cost diaries were representative for that period (Goossens et al. 2000). Subsequently, the annual costs per family were multiplied by the Dutch prevalence figure for anxiety disorders, which is $9.7 \%$ (Verhulst et al. 1997) and the percentage of referred children of 3.5\% (Verhulst and van der Ende 1997), which results in a multiplication factor of $0.34 \%$, to calculate the total annual societal cost-of-illness of families of clinically anxious children referred for treatment. It was assumed that the percentage of referred children with a mental disorder (3.5\%) could be attributed to anxiety disorders as well. Furthermore, a low and high estimation of the costof-illness was calculated. The low multiplication factor of $0.08 \%$ was derived by multiplying the low prevalence rate of children with a mental disorder seeking treatment in mental health care of $1.6 \%$ with the low prevalence rate of impairment in functioning of $5 \%$ (i.e. $1.6 \times 5 \%$ ). The high multiplication factor of $0.81 \%$ was derived by taking the high prevalence rate of children with a mental disorder 
seeking treatment in mental health care of $8.1 \%$ and multiply this with the high prevalence rate with impairment in functioning of $10 \%$ (i.e. $8.1 \times 10 \%$ ).

\section{Discriminative Validity}

To determine the discriminative validity of the prospective cost diary, the societal costs of the 118 families of anxious children were compared to the societal costs of 41 families from the general population. For this purpose, all costs related to the child, irrespective of reason, were taken into account (i.e. psychological, physical or other). For both groups, the costs per family over a period of 2 weeks were extrapolated to a period of 1 year to obtain the annual costs per child for both groups. It was hypothesized that costs for anxiety problems were higher in the clinically anxious group compared to the general population but comparable between the two groups for psychological, physical and other problems.

\section{Convergent Validity}

To establish convergent validity, health care costs per child per year obtained with the prospective cost diaries of 118 clinically anxious children were compared with the health care costs of children with a primary diagnosis of anxiety disorder, according to top-down registrations. For this comparison, only health-care costs due to anxiety of the child were considered, because the costs obtained with the top-down registration applied to children with a primary diagnosis of anxiety disorder and only consisted of costs related to the health care sector.

The top-down data were obtained from a generic cost study based on national registrations (Polder et al. 2002). In this study, the total costs of health care in 1999 were assigned to diagnosis groups based on actual delivered care, according to distribution codes which are chosen in such a way that they represent equal units of care. These distribution codes are adjusted to the best available data about the care usage (for more details see Polder et al. 2002). This was done for each of the 21 health care sectors including the mental health care sector. Diagnosis groups were based on the International Statistical Classification of Diseases, injuries and causes of death (ICD-9; World Health Organization 1977). The ICD-9 is divided into 17 chapters, including chapter $\mathrm{V}$, mental and behavioural disorders. Furthermore, a more intricate classification is used, by itemizing the chapters into 96 specific diagnosis groups, including anxiety disorders. All anxiety disorders are taken into account (ICD-9 300.0-3 and 300.5-9) (World Health Organization 1977).

The top-down data could not be compared directly to the group of 8-18 year old children included in the bottom-up cost-of-illness analysis, because costs were presented for the age groups 5- to 9-, 10- to 14- and 15- to 19-year-olds. Therefore, the assumption was made that costs were equally distributed within the age groups, so the corresponding ages (8-18) could be filtered out by averaging the costs and multiplying them by each age year (Polder et al. 2002). Since top-down data were based on costs in 1999, for comparison with the bottom-up cost-of-illness approach, costs were actualized to 2003 euros by using the Consumer Price Index (CPI; Statistics Netherlands 2005).

\section{Statistical Analysis}

Statistical analysis could only be performed on the costof-illness study and on the discriminative validity study, since top-down data were not available on child level. Missing items in the cost diaries were handled with the Missing Value Analysis of SPSS based on the regression models using available data of the group mean, the available data of the individual and the pattern of change of the group. To investigate whether data were normally distributed, a Kolmogorov-Smirnov test was performed. Due to highly skewed cost distributions, bootstrap simulations were conducted in order to get insight in significant differences on subtotal and total costs between families of clinically anxious children and families from the general population and the uncertainty surrounding these costs. The bootstrap method estimates the sampling distribution of a statistic through 1,000 simulations, based on sampling with replacement from the original data (Briggs, Wonderling and Mooney 1997). Bootstrap methods are increasingly being used for analysis of cost data, as traditional parametric and nonparametric statistical methods to analyse the difference in mean costs between groups may be inappropriate when data are skewed (Barber and Thompson 2000; Desgagné et al. 1998).

\section{Results}

\section{Cost-of-illness}

All resources used and costs made related to the anxiety of the child by families with a clinically anxious child were summed and averaged for 2 weeks and 1 year (Table 1). The mean costs per family over 2 weeks were extrapolated to a year and amounted to $€ 2748$ per family with a clinically anxious child. Costs were not normally distributed, Kolmogorov-Smirnov $Z=4.5, p<0.01$, and skewed to the left, indicating that a minority of families $(n=25,21 \%)$ reported costs related to the anxiety of the child. A logistic regression was performed using families with and without costs as the dependent variable and age, gender, severity 
Table 1 Mean total resource use, subtotal and total societal costs due to anxiety reasons using a bottom-up approach $(n=118)$

\begin{tabular}{|c|c|c|c|c|c|}
\hline & Costs per unit & $\begin{array}{l}\text { Total resource } \\
\text { use ( } 2 \text { weeks) }\end{array}$ & $\begin{array}{l}\text { Total costs } \\
\text { ( } 2 \text { weeks) }\end{array}$ & $\begin{array}{l}\text { Total costs } \\
\text { per child } \\
(2 \text { weeks })\end{array}$ & $\begin{array}{l}\text { Total costs } \\
\text { per child a year }\end{array}$ \\
\hline & & Sum & Sum & $M(\mathrm{SD})$ & $M(\mathrm{SD})$ \\
\hline \multicolumn{6}{|l|}{ Direct health care costs } \\
\hline Psychologist & $124 /$ contact $^{1}$ & 0.00 & 0.00 & 0.00 & 0.00 \\
\hline Psychiatrist & $76.00 /$ contact $^{1}$ & 0.00 & 0.00 & 0.00 & 0.00 \\
\hline G.P practice & $20.20 /$ contact $^{1}$ & 3.00 & 60.60 & $0.51(4.14)$ & $13.35(108)$ \\
\hline G.P. telephone & $10.10 /$ contact $^{1}$ & 1.00 & 10.10 & $0.09(0.93)$ & $2.23(57.98)$ \\
\hline Anxiety medication & $0.72 / \mathrm{ddd}^{2}$ & 14.25 & 10.26 & $0.09(0.50)$ & $2.26(13.00)$ \\
\hline Pharmacists fee & $6.45 /$ med. $^{1}$ & 14.25 & 91.91 & $0.78(4.50)$ & $20.28(117)$ \\
\hline Institutionalized treatment & $164 /$ day $^{5}$ & 20.00 & 3,286 & $27.85(213)$ & $724(5,537)$ \\
\hline Day treatment & $95.87 /$ day $^{5}$ & 30.00 & 2,876 & $24.37(152)$ & $634(3,940)$ \\
\hline Subtotal & & & 6,335 & $53.69(261)$ & $1,396(6,773)$ \\
\hline Bootstrapped subtotal & & & & $52.78(24.05)$ & $1,371(583)$ \\
\hline \multicolumn{6}{|l|}{ Direct non-health care costs } \\
\hline Paid house keeper & $12.70 / \mathrm{h}^{1}$ & 2.00 & 25.44 & $0.22(2.34)$ & $5.61(60.84)$ \\
\hline Informal care & $8.30 / \mathrm{h}^{1}$ & 32.00 & 269 & $2.28(19.04)$ & $59.23(495)$ \\
\hline Subtotal & & & 294 & $2.50(19.16)$ & $64.84(498)$ \\
\hline Bootstrapped subtotal & & & & $2.43(1.76)$ & $68.15(47.59)$ \\
\hline \multicolumn{6}{|l|}{ Indirect costs } \\
\hline Paid work & $34.98 / \mathrm{h}^{1}$ & 83.29 & 2,888 & $24.48(154)$ & $636(4003)$ \\
\hline Unpaid work & $8.30 / \mathrm{h}^{1}$ & 4.00 & 33.60 & $0.28(3.09)$ & $7.40(80.34)$ \\
\hline Loss of leisure time & $8.30 / h^{1}$ & 43.00 & 361 & $3.06(16.47)$ & $79.59(428)$ \\
\hline Household work & $8.30 / \mathrm{h}^{1}$ & 6.50 & 54.60 & $0.46(4.03)$ & $12.03(105)$ \\
\hline School absence & $4.37 / \mathrm{h}^{3}$ & 474 & 2,070 & $17.55(57.89)$ & $456.20(1,505)$ \\
\hline Subtotal & & & 5,408 & $45.83(198)$ & $1,191.64(5,135)$ \\
\hline Bootstrapped subtotal & & & & $46.12(18.22)$ & $1,193.64(473)$ \\
\hline \multicolumn{6}{|l|}{ Out-of-pocket costs } \\
\hline Transportation & $0.16 / \mathrm{km}^{1}$ & 126 & 20.20 & $0.17(1.41)$ & $4.42(36.66)$ \\
\hline Own contribution alternative treatment & & & 350 & $2.97(32.22)$ & $77.12(838)$ \\
\hline Own contribution medication not prescribed & & & 63.30 & $0.54(5.83)$ & $13.95(152)$ \\
\hline Subtotal & & & 434 & $3.67(38.22)$ & $95.52(994)$ \\
\hline Bootstrapped subtotal & & & & $3.86(36.48)$ & $97.52(94.08)$ \\
\hline Total costs & & & 12,471 & $106(340)$ & $2,748(8,841)$ \\
\hline Bootstrapped total costs & & & & $104(32.45)$ & $2,749(815)$ \\
\hline
\end{tabular}

${ }^{1}$ Source of volume price: Oostenbrink et al. $2004,{ }^{2}$ Gip databank, ${ }^{3}$ Nibud, ${ }^{4}$ Cost diary, ${ }^{5}$ Actual costs

and number of diagnoses as covariates within an enter method. When comparing families who reported costs to families who reported no costs, binary logistic regression revealed only one main effect for age, corrected for gender, severity and number of diagnoses, Wald $(1)=11.4, p<0.01$, O. $\mathrm{R} .=1.4$. No main effect was found for gender, severity or number of diagnoses, Wald (1) $\mathrm{s}<0.2, p \mathrm{~s}>0.1$. This indicates that in families who reported costs related to the child's anxiety, the child was older compared to families who reported no costs, irrespective of gender, severity and number of diagnoses. The main contributor to costs were costs related to institutionalized treatment ( $26 \%$ of total costs), day treatment ( $23 \%$ of total costs), productivity loss of the parents (23\% of total costs) and school absence (17\% of total costs).

The total number of Dutch children aged 8-18 in 2003 was computed using data of the Statistics Netherlands
(2005), and resulted in 2,175,382 children. Multiplying this figure by $0.34 \%$ resulted in 7,385 Dutch children with an anxiety disorder that interferes with daily functioning and who are referred to treatment. Hence, the annual societal cost-of-illness accumulated to $€ 2,748 \times 7,385=€ 20,293,958$ for families of clinically anxious children referred for treatment in the Netherlands. The same calculation was performed using the low and high multiplication factors. This resulted in a low estimate of the cost-of-illness of $€ 4,783,839$ and a high estimate of $€ 48,436,370$.

\section{Discriminative Validity}

The mean total annual societal costs related to anxiety, psychological, physical and other reasons for families with 
a clinically anxious child and families from the general population are presented in Table 2 . In the clinically anxious group, costs due to anxiety reasons were highest ( $89 \%$ of total costs), followed by costs due to physical reasons ( $6 \%$ of total costs), costs due to other reasons $(3 \%$ of total costs) and psychological reasons ( $3 \%$ of total costs). The total annual costs of families with clinically anxious children due to anxiety problems, psychological problems, physical problems and other amounted to a mean of $€ 3,084$ $(\mathrm{SD}=8,945)$ per child.

Costs of families from the general population were highest for physical reasons ( $95 \%$ of total costs). A small proportion of costs was assigned to psychological reasons (5\% of total costs) and other reasons ( $0.2 \%$ of total costs).
Despite the fact that five children in the control group met criteria for an anxiety disorder, families reported no costs for anxiety reasons. The total annual costs obtained from families of the general population amounted to a mean of $€ 148(\mathrm{SD}=523)$ per family.

Costs in both groups were not normally distributed (Kolmogorov-Smirnov $Z>1.6, p<0.05$ ). The bootstrapped results indicated that total societal costs were significantly higher in families with clinically anxious children compared to families from the general population. Subdividing the costs into reason showed significant higher costs related to anxiety and other reasons in families with a clinically anxious child compared to families from the general population. Costs related to psychological reasons were

Table 2 Subtotal and total costs for clinically anxious children and children from the general population per year using a bottom-up approach $(n=118)$

\begin{tabular}{|c|c|c|c|c|c|c|c|c|c|c|}
\hline & \multicolumn{2}{|c|}{ Anxiety reason } & \multicolumn{2}{|c|}{ Psychological reason } & \multicolumn{2}{|c|}{ Physical reason } & \multicolumn{2}{|c|}{ Other reason } & \multicolumn{2}{|c|}{ Total a year } \\
\hline & Cl. anx. & Gen. & Cl. anx. & Gen. & Cl. anx. & Gen. & Cl. anx. & Gen. & Cl. anx. & Gen. \\
\hline \multicolumn{11}{|l|}{ Direct health care costs } \\
\hline Psychologist/psychiatrist & 0.00 & 0.00 & 0.00 & 0.00 & 0.00 & 0.00 & 0.00 & 0.00 & 0.00 & 0.00 \\
\hline G.P practice & 13.35 & 0.00 & 4.45 & 0.00 & 13.35 & 0.00 & 0.00 & 0.00 & 28.86 & 0.00 \\
\hline G.P. telephone & 2.23 & 0.00 & 2.23 & 0.00 & 4.45 & 0.00 & 0.00 & 0.00 & 8.84 & 0.00 \\
\hline Hospital visit & 0.00 & 0.00 & 0.00 & 0.00 & 34.37 & 98.80 & 17.19 & 0.00 & 51.48 & 98.80 \\
\hline Emergence visit hospital & 0.00 & 0.00 & 0.00 & 0.00 & 30.63 & 0.00 & 0.00 & 0.00 & 30.68 & 0.00 \\
\hline Medication & 2.26 & 0.00 & 2.29 & 0.00 & 6.80 & 4.68 & 0.22 & 0.00 & 11.70 & 4.68 \\
\hline Pharmacist fee & 20.25 & 0.00 & 18.48 & 0.00 & 29.84 & 20.54 & 1.42 & 0.00 & 69.94 & 20.54 \\
\hline Day treatment & 634 & 0.00 & 0.00 & 0.00 & 0.00 & 0.00 & 0.00 & 0.00 & 634 & 0.00 \\
\hline Institutionalized treatment & 724 & 0.00 & 0.00 & 0.00 & 0.00 & 0.00 & 0.00 & 0.00 & 724 & 0.00 \\
\hline Subtotal & 1,396 & 0.00 & 27.44 & 0.00 & 119 & 124 & 18.83 & 0.00 & 1,559 & 124 \\
\hline Bootstrapped subtotal & & & & & & & & & 1,521 & 124 \\
\hline \multicolumn{11}{|l|}{ Direct non-health care costs } \\
\hline House keeper & 5.61 & 0.00 & 0.00 & 0.00 & 0.00 & 0.00 & 8.41 & 0.00 & 14.04 & 0.00 \\
\hline Informal care & 59.23 & 0.00 & 0.00 & 0.00 & 0.00 & 0.00 & 14.81 & 0.00 & 74.10 & 0.00 \\
\hline Subtotal & 64.83 & 0.00 & 0.00 & 0.00 & 0.00 & 0.00 & 23.21 & 0.00 & 88.05 & 0.00 \\
\hline Bootstrapped subtotal & & & & & & & & & 87.21 & 0.00 \\
\hline \multicolumn{11}{|l|}{ Indirect costs } \\
\hline Paid work & 636 & 0.00 & 0.00 & 0.00 & 0.00 & 0.00 & 7.67 & 0.00 & 644 & 0.00 \\
\hline Unpaid work & 7.40 & 0.00 & 0.00 & 0.00 & 0.00 & 0.00 & 0.00 & 0.00 & 7.28 & 0.00 \\
\hline Leisure time loss & 79.59 & 0.00 & 0.00 & 0.00 & 0.00 & 0.00 & 0.00 & 0.00 & 79.56 & 0.00 \\
\hline Household work & 12.03 & 0.00 & 0.00 & 0.00 & 0.00 & 0.00 & 0.00 & 0.00 & 11.96 & 0.00 \\
\hline School absence & 456 & 0.00 & 51.01 & 0.00 & 48.60 & 0.00 & 15.88 & 0.00 & 572 & 0.00 \\
\hline Subtotal & 1,192 & 0.00 & 51.01 & 0.00 & 48.60 & 0.00 & 23.55 & 0.00 & 1,315 & 0.00 \\
\hline Bootstrapped subtotal & & & & & & & & & 1,305 & 0.00 \\
\hline \multicolumn{11}{|l|}{ Out-of-pocket costs } \\
\hline Transportation & 4.45 & 0.00 & 0.76 & 0.00 & 3.68 & 0.00 & 0.85 & 0.00 & 9.62 & 0.00 \\
\hline Alcohol & 0.00 & 0.00 & 0.00 & 0.00 & 0.00 & 0.00 & 11.13 & 0.29 & 11.18 & 0.29 \\
\hline Caffeine & 0.00 & 0.00 & 0.00 & 0.00 & 0.50 & 0.00 & 0.78 & 0.00 & 1.30 & 0.00 \\
\hline Tobacco & 0.00 & 0.00 & 0.00 & 0.00 & 0.00 & 0.00 & 7.40 & 0.00 & 7.28 & 0.00 \\
\hline Own expenses & 91.07 & 0.00 & 0.00 & 7.29 & 1.38 & 16.49 & 0.00 & 0.00 & 92.56 & 23.66 \\
\hline Subtotal & 95.52 & 0.00 & 0.76 & 7.29 & 5.55 & 16.49 & 20.16 & 0.29 & 122 & 23.92 \\
\hline Bootstrapped subtotal & & & & & & & & & 125 & 23.89 \\
\hline Total costs & 2,748 & 0.00 & 79.21 & 7.29 & 174 & 141 & 85.75 & 0.29 & 3,084 & 148 \\
\hline Bootstrapped total & 2,790 & 0.00 & 78.44 & 7.23 & 173 & 142 & 86.99 & 0.32 & 3,070 & 147 \\
\hline Incremental costs $(95 \% \mathrm{CI})$ & \multicolumn{2}{|c|}{$-2,790(-4,530$ to $-1,336)$} & \multicolumn{2}{|c|}{$-71(-205$ to 0$)$} & \multicolumn{2}{|c|}{$-31(-199$ to 131$)$} & \multicolumn{2}{|c|}{$-87(-152$ to -33$)$} & \multicolumn{2}{|c|}{$-2,923(-4,505$ to $-1,470)$} \\
\hline
\end{tabular}


borderline significantly higher for the families with a clinically anxious child (see Table 2).

\section{Convergent Validity}

The total health care costs of 8- to 18-year-old children with a primary diagnosis of anxiety disorder amounted to $€ 8,018,000$ in 1999 using the top-down approach, which augmented to $€ 9,075,613$ in 2003 when corrected with CPI. The total number of anxious 8- to 18-year-old children referred for treatment in 2003 was 7,385 (i.e. $2,175,382 \times$ $0.34 \%$ ). Dividing the total health care costs due to anxiety in children by this number resulted in $€ 1,229$ per anxious child that was referred (see Table 3 ).

Direct health care costs derived from the bottom-up method were used to compare with the top-down approach and amounted to $€ 1,410$ per referred anxious child (see Table 3). Total health care costs for clinically anxious children resulted in $€ 10,412,187$ with a low estimate of $€ 2,453,541$ and a high estimate of $€ 24,842,036$. Although the overall difference in total health care costs between the bottom-up and top-down approach per anxious child per year were about $€ 180$ (top-down 13\% lower than bottomup), the differences in costs per health care sector were considerably higher. For instance, costs of medical hospital care were $€ 287$ higher using the top-down approach $(23 \%$ of total costs) compared to costs obtained with the bottomup approach ( $0 \%$ of total costs). On the other hand, mental health care costs were $€ 573$ higher (top-down $42 \%$ lower than bottom-up) using the bottom-up approach ( $96 \%$ of total costs) compared to the costs obtained with the topdown approach $(64 \%$ of total costs).

Table 3 Direct health care costs, anxiety based per child a year based on the Bottom-up and top-down approach

\begin{tabular}{lcc}
\hline & $\begin{array}{l}\text { Bottom-up } \\
\text { costs }\end{array}$ & $\begin{array}{l}\text { Top-down } \\
\text { costs }\end{array}$ \\
\hline A day of hospitalization & 0.00 & 203 \\
Day treatment & 0.00 & 1.84 \\
Polyclinic visit & 0.00 & 42.51 \\
Categorical hospital & 0.00 & 32.71 \\
Remaining & 0.00 & 7.60 \\
$\quad$ Subtotal hospital care & 0.00 & 287 \\
General practitioner & 15.58 & 58.27 \\
Paramedical care & 0.00 & 1.23 \\
$\quad$ Subtotal Primary care & 92.70 & 59.50 \\
Pharmaceutical help & 36.49 & 67.50 \\
Mental health care & 1,358 & 785 \\
Management and care insurances & 0.00 & 29.92 \\
Total costs & 1,410 & 1,229 \\
\hline
\end{tabular}

\section{Discussion}

To the authors' knowledge, this is the first cost-of-illness study in clinically anxious children referred for treatment. The aim of this study was threefold. The first aim was to measure the societal costs of illness in clinically anxious children and their families, using a bottom-up approach by means of a prospective cost diary. The second aim was to investigate the discriminative validity of the prospective cost diary by comparing the costs of families with a clinically anxious child to the costs of families from the general population. The third aim of the study was to establish convergent validity by comparing bottom-up acquired health care costs of the clinically anxious children with top-down acquired health care costs of children with a primary diagnosis of anxiety.

With respect to results regarding cost-of-illness, bottomup acquired total societal costs for families of clinically anxious children referred for treatment amounted to more than $€ 20$ million per year in the Netherlands with a low estimation of 4.8 and a high estimation of 48 million euros, which is a quite broad range. Costs amounted to $€ 2,748$ per family with a clinically anxious child per year. These costs seem relatively low compared to costs of other childhood psychopathology. Knapp et al. (1999) conducted a pilot study on ten children aged 4-10 with conduct disorders. Cost amounted to $€ 22,272$ per family per year, which is about eight times as high as the costs per family with a clinically anxious child in our study. However, a more elaborate study $(n=80)$ on 3 - to 8 -year-old children with anti-social behaviour (Romeo et al. 2006), reported lower mean annual total costs, namely $€ 8781$ per child, still 3.2 times higher than those of anxious children. In another study on 11 children with autism spectrum disorders, societal costs were $€ 51,844$ per child per year (Järbrink et al. 2003), which is 19 times higher than the costs per anxious child. It should be noted that the prevalence rate for anxiety is almost four times as high as conduct disorder (2.6\%, Verhulst et al. 1997) and 39 to 44 times higher than the prevalence rate for autism spectrum disorders $(0.22-$ $0.25 \%$, van der Gaag et al. 1996). Consequently, the relative costs for society of childhood anxiety disorders, combining absolute costs with prevalence, are similar to conduct disorders and higher than those of autism spectrum disorders.

In line with Knapp et al. (1999), Romeo et al. (2006) and Järbrink et al. (2003) a large part of the costs in our study can be attributed to the parents' productivity loss due to anxiety disorders of the child ( $23 \%$ of total costs). Knapp et al. (1999) found that per family with a child with conduct disorder, the annual costs due to lost employment were $€ 5,683$ (30\% of the total costs). Costs to the family related to extra time spend on household tasks, the need for repairs 
and time off work due to the anti-social behaviour of the child were $€ 4,637$, which is $78 \%$ of the total costs. Järbrink et al. (2003) showed that more than $50 \%$ of the total costs of children with an autism spectrum disorder were attributable to parents and costs related to income loss were $€ 17,405$ (34\% of total costs). Our study also found high costs due to school absenteeism (17\% of total costs). School absence can have long-term economic consequences such as decreased job opportunities or even unemployment. Taken together, both productivity costs of parents and school absence costs of children seem very important and should be considered in future costing studies. Furthermore, logistic regression analysis revealed that in families with costs related to the child's anxiety, the child was older compared to families with no costs, irrespective of gender, severity and number of diagnoses. This is in line with the finding that top-down health care costs related to anxiety disorders and health care costs in general increase with age (Polder et al. 2002). Perhaps older children are more prone to react against their parents and are more independent, thereby reducing the influence of parents (Hudson et al. 2002). It can be speculated that less influence from the parents may lead to more school absenteeism among older children. Indeed, 39\% of the children aged 18-24 reported school absenteeism in the last 2 months compared to $13 \%$ of the children aged 12-17 (Statistics Netherlands 2005). Also, the older child may be more aware of the anxiety complaints, possibly increasing the costs of mental health care. Future research should investigate this issue more profoundly.

An additional finding of this study concerns the difference in measuring costs in children with anxiety disorders compared to cost-of-illness studies in adults with anxiety disorders. The main difference of measuring costs in children with anxiety disorders, as other mental disorders in children, is that anxiety in the child does not only affect the child, but also the child's family. Therefore, the costs concerning the child's anxiety should also be measured at the family level. Although many would argue that the costs of illness for adults spill over to the family as well, studies on costs of anxiety disorders in adults usually do not include family members, especially not their children. So, in future research it may be interesting to assess the costs of adult anxiety disorders on a family level as well. For example, they might be more protective of their children and therefore increase their children's health care consumption or more often let their child miss a day from school. Moreover, in adult cost-of-illness studies, productivity losses due to absence of paid work are measured. In children, these kind of productivity losses do not occur. However, alternatives such as costs due to absence from school should be taken into account, since school participation can be regarded as a productive activity, and (regular) absence from school may serve as a proxy for future productivity losses.
With respect to the results regarding discriminative validity, total costs of families with clinically anxious children using a bottom-up approach were almost 21 times higher than costs of families from the general population. In line with the hypothesis, the difference in costs between families of clinically anxious children and families from the general population can largely be subscribed to the significant difference in anxiety-related costs, showing good discriminative validity of the cost diary on anxiety related costs. However, significant differences were also found on costs due to other reasons. In the prospective cost diary, the reasons for resource use were recorded based on subjective judgments by the parents. However, since anxiety is an internalizing disorder, parents may not always have been able to interpret children's symptoms correctly. Therefore, they may have attributed costs mistakenly to non-anxiety reasons. For example, parents regularly reported a baby-sitter for a child old enough to stay on its own, if the child would not have been anxious. Another item that was reported as not being related to anxiety was extra travel expenses for the separation anxious child, who otherwise could have stayed at home.

With respect to convergent validity, total direct health care costs related to anxiety were $13 \%$ lower using a topdown approach than using a bottom-up approach, which seems quite comparable. However, subdividing the costs into several cost categories showed that costs were distributed differently among the cost categories. For example, bottom-up acquired mental health care costs were $58 \%$ higher than top-down acquired mental health care costs. Furthermore, $23 \%$ of the total costs using a top-down approach were attributed to hospital care, whereas no hospital care costs were found using the bottom-up approach. Hence, convergent validity on total direct health care costs were quite comparable, while the specific cost categories differed between bottom-up and the top-down approach. These findings suggest that children, who are not yet referred for mental health care, might consume more medical hospital care compared to children who are referred for mental health care. Therefore, from a cost-of-illness perspective, it would also be interesting to investigate costs of families with children with anxiety disorders who are not referred for mental health treatment, using the cost dairy developed for this study. It might well be that these families have more medical health care costs, as the comparison with top-down acquired data suggests.

This study has some limitations, which should be addressed. The first limitation is that the low and high multiplication factor used in this study caused a broad range of the societal costs of illness. This can be explained by the broad range of internationally reported prevalence rates and percentages of children seeking treatment due to differences in measurements, populations, and criteria that need to be 
fulfilled. As a Dutch population was investigated, the most appropriate prevalence rate is $9.7 \%$ (Verhulst et al. 1997), which was obtained through the use of a reliable structured diagnostic interview. The same is true for the $3.5 \%$ of children with mental disorders seeking treatment (Verhulst and van der Ende 1997). Besides, 4\% of the Dutch people with anxiety disorders are referred for further treatment by their general practitioner (van Wieren et al. 2007). Therefore, the prevalence and referral rates used in this study seem reliable.

The second limitation of the current study is that it can be argued that 2-week cost diaries filled in by parents are not representative enough to reliably assess 1 -year bottom-up costs due to the limited time period. However, Goossens et al. (2000) have found that keeping a diary in a limited period namely 1 week every month, 2 weeks every 2 months or an entire year resulted in similar outcomes in fibromyalgia and pain patients. Another study of Bruijnzeels et al. (1998b) found that there was a substantial agreement between a 3 -week cost diary, filled in by parents, and medical records concerning general practitioner visits of children. Moreover, the inclusion period of this study lasted 2 years in which the cost diaries were filled out, therefore possible seasonal influences are ruled out. However, it is likely that service use patterns may vary over the year and do not follow a stable trajectory. So, for some families the 2-weeks period for collecting costs may have led to an underestimation of the total annual costs, whereas for other families this may have led to an overestimation of the total annual costs. Nevertheless, as the mean annual costs are based on cost data from each of these families, it is expected that possible overand underestimations of annual costs are balanced.

The third, and most serious, limitation of this study is that although total health care costs obtained with the topdown and bottom-up method seemed quite comparable, the sample of children with a primary diagnosis of anxiety disorder used in the top-down study by Polder et al. (2002) might not be fully comparable to the clinically anxious children from our bottom-up approach in at least three respects. First, the children in the bottom-up sample were clinically anxious children with severe anxiety disorders. The mean number of anxiety disorders was 3 and the mean severity level 7 , indicating severe interference with daily functioning. The children with a primary diagnosis of anxiety disorder in the top-down sample might suffer from different levels of anxiety disorders; some may have minor anxiety problems, while others may have severe anxiety problems. This kind of information was not available using the top-down data. Second, while the clinically anxious children in the bottom-up sample were awaiting CBT in a community mental health care setting, the anxious children in the top-down sample might be in different types and/or phases of treatment. Again, this kind of information was not available using the top-down data. Third, the clinically anxious children in the bottom-up sample were diagnosed using a universally used semi-structured interview, the ADIS which is based on DSM-IV criteria (American Psychiatric Association 1994). In the top-down sample, children were diagnosed by the doctor in attendance, who attributed the anxiety diagnosis to the patient based on the ICD-9 code, without a structured interview. Due to the classification method, the top-down estimation is possibly less reliable than the bottom-up cost estimation. Therefore, results of the comparison between top-down and bottom-up costs should be interpreted with caution.

In conclusion, this cost-of-illness study shows that the societal costs of families with a clinically anxious child who seek treatment amount to more than 20 million euros a year in the Dutch population, and were 21 times higher than in families of the general population. An effective treatment could decrease these costs on the long term. A recent costeffectiveness study on family CBT versus individual CBT showed that societal costs in families with a clinically anxious child increased during treatment (due to total costs of 12 sessions CBT a $€ 1,612$ ) but decreased directly after treatment to baseline level. Even more, during the 1-year follow-up societal costs dropped below the costs at baseline (Bodden et al. submitted for publication). Since anxiety disorders tend to last into adulthood (Newman et al. 1996), societal costs are likely to be higher at the long term. This results in anxiety disorders accounting for the highest costs of all mental illnesses in adulthood in the USA (Dupont et al. 1996). Hence, societal costs in adults with anxiety disorders may be saved by providing effective treatments to children with clinical anxiety disorders.

Acknowledgement This study was financially supported by a grant from ZonMw, the Netherlands organisation for health research and development, grant number 945-02-052. The data for this study have been collected while the first and third author worked at the University of Maastricht.

Open Access This article is distributed under the terms of the Creative Commons Attribution Noncommercial License which permits any noncommercial use, distribution, and reproduction in any medium, provided the original author(s) and source are credited.

\section{References}

Ament, A., \& Evers, S. (1993). Cost-of-illness studies in health care: A comparison of two cases. Health Policy, 26, 29-42.

American Psychiatric Association. (1994). Diagnostic and statistical manual of mental disorders (4th edn.). Washington, DC: American Psychiatric Association.

Anderson, J. C., Williams, S., McGee, R., \& Silva, P. A. (1987). DSM-III disorders in preadolescent children. Archives of General Psychiatry, 44, 69-76. 
Barber, J. A., \& Thompson, S. G. (2000). Analysis of cost data in randomized trials: An application of the non-parametric bootstrap. Statistics in Medicine, 19, 3219-3236.

Board Tariff Rates Health Care and Care Authority (College Tarieven Gezondheidszorg Zorgautoriteit in oprichting) (2005). http:// www.ctg-zaio.nl.

Board of Health Insurances (College voor Zorgverzekeringen) (2005). Medication and aid information project (Genees - en hulpmiddelen Informatie Project databank). http://www.gipdatabank.nl.

Briggs, A. H., Wonderling, D. E., \& Mooney, C. Z. (1997). Pulling cost-effectiveness analysis up by its bootstraps: A non-parametric approach to confidence interval estimation. Health Economics, 6, 327-340.

Bruijnzeels, M. A., Foets, M., van der Wouden, J. C., Prins, A., \& van den Heuvel, W. J. A. (1998a). Measuring morbidity of children in the community: A comparison of interview and diary data. International Journal of Epidemiology, 27, 96-100.

Bruijnzeels, M. A., van der Wouden, J. C., Foets, M., Prins, A., \& van den Heuvel, W. J. A. (1998b). Validity and accuracy of interview and diary data on children's medical utilization in The Netherlands. Journal of Epidemiology and Community Health, 52, 65-69.

Byford, S., McDaid, D., \& Sefton, T. (2003). Because its worth it: A practical guide to conducting economic evaluations in the social welfare field. York: Joseph Rowntree Foundation.

Desgagné, A., Castilloux, A. M., Angers, J. F., \& LeLorier, J. (1998). The use of bootstrap statistical method for the pharmacoeconomic cost analysis of skewed data. Pharmacoeconomics, 13, 487-497.

Dupont, R. L., Rice, D. P., Miller, L. S., Shiraki, S. S., Rowland, C. R., \& Harwood, H. J. (1996). Economic costs of anxiety disorders. Anxiety, 2, 167-172.

Finkler, S. A. (1982). The distinction between cost and charges. Annals of Internal Medicine, 96, 102-109.

Freer, C. B. (1980). Health diaries: A method of collecting health information. Journal of the Royal College of General Practitioners, 30, 279-282.

Goossens, M. E. J. B., Rutten-van Mölken, M. P. M. H., Vlaeyen, J. W. S., \& Van der Linden, S. M. J. P. (2000). The cost diary: A method to measure direct and indirect costs in cost-effectiveness research. Journal of Clinical Epidemiology, 53, 688-695.

Greenberg, P. E., Sisitsky, T., Kessler, R. C., Finkelstein, S. N., Berndt, E. R., Davidson, J. R. T., et al. (1999). The economic burden of anxiety disorders in the 1990s. Journal of Clinical Psychiatry, 60, 427-435.

Hudson, J. L., Kendall, P. C., Coles, M. E., Robin, J. A., \& Webb, A. (2002). The other side of the coin: Using intervention research in child anxiety disorders to inform developmental psychopathology. Developmental Psychopathology, 14, 819-841.

Järbrink, K., Fombonne, E., \& Knapp, M. (2003). Measuring the parental, service and cost impacts of children with autistic spectrum disorder: A pilot study. Journal of Autism and Developmental Disorders, 33, 395-402.

Kessler, R. C., McGonagle, K. A., Zhao, S., Nelson, C. B., Hughes, M., Eshleman, S., et al. (1994). Lifetime and 12-month prevalence of DSM-III-R psychiatric disorders in the United States. Archives of General Psychiatry, 51, 8-19.

Klein, R. G., \& Pine, D. S. (2002). Anxiety disorders. In M. Rutter \& E. Taylor (Eds.) Child and adolescent psychiatry, (4th edn.) (pp. 486510). Oxford: Blackwell Publishing.

Knapp, M., Scott, S., \& Davies, J. (1999). The cost of antisocial behaviour in younger children. Clinical Child Psychology and Psychiatry, 4, 457-473.

Leaf, P. J., Alergia, M., Cohen, P., Goodman, S. H., Horwitz, S. M., Hoven, C. W., et al. (1996). Mental health service use in the community and schools: Results from the four-community MECA study. Child and Adolescent Psychiatry, 35, 889-897.

Leon, A. C., Portera, L., \& Weissman, M. M. (1995). The social costs of anxiety disorders. British Journal of Psychiatry, 27, 19-22.

National Institute of Budget information (Nationaal Instituut voor Budgetvoorlichting, NIBUD) (2005). http://www.nibud.nl.

Newman, D. L., Moffitt, T. E., Caspi, A., Magdol, L., et al. (1996). Psychiatric disorder in a birth cohort of young adults: Prevalence, comorbidity, clinical significance, and new incidence from ages $11-$ 21. Journal of Consulting and Clinical Psychology, 64, 552-562.

Oostenbrink, J. B., Koopmanschap, M. A., \& Rutten, F. F. H. (2004). Handleiding voor kostenonderzoek: Methoden en richtlijnprijzen voor economische evaluaties in de gezondheidszorg. Amstelveen: College voor zorgverzekeringen. Geactualiseerde versie 2004.

Polder, J. J., Takken, J., Meerding, W. J., Kommer, G. J., \& Stokx, L. J. (2002). Kosten van ziekten in Nederland. http://www.rivm.nl/ kostenvanziekten.

Rice, D. P., \& Miller, L. S. (1995). Health economies and cost implications of anxiety and other mental disorders in the US. British Journal of Psychiatry, 173, 4-9.

Romeo, R., Knapp, M., \& Scott, S. (2006). Economic cost of severe antisocial behaviour in children-And who pays it. British Journal of Psychiatry, 188, 547-553.

Siebelink, B. M., \& Treffers, Ph.D.A. (2001). Nederlandse bewerking van het Anxiety Disorder Interview Schedule for DSM-IV: Child version van W.K. Silverman en A.M. Albano. Lisse/Amsterdam: Swets \& Zeitlinger.

Silverman, W. K., \& Albano, A. M. (1996). Anxiety disorders interview schedule for DSM-IV child version, Child interview schedule. San Antonio: The Psychological Corporation.

Silverman, W. K., Saavedra, L. M., \& Pina, A. A. (2001). Test-retest reliability of anxiety symptoms and diagnoses with anxiety disorders interview schedule for DSM-IV: Child and parent versions. Journal of the American Academy of Child and Adolescent, 40, 937-944.

Sleed, M., Eccleston, C., Beecham, J., Knapp, M., \& Jordan, A. (2005). The economic impact of chronic pain in adolescence: Methodological considerations and preliminary costs-of-illness study. Pain, 119, 183-190.

Statistics Netherlands (Centraal Bureau voor Statistiek, CBS). (2005). Retrieved 2005 from http://www.cbs.nl.

Sytema, S., \& Koopmans, P. (1998). Psychische stoornissen in de volwassen bevolking; een verkenning van omvang, gevolgen en kosten. Den Haag: SDU uitgevers.

van der Gaag, R. J., Robbroeckx, L., Smid, G. A., \& Verhulst, F. C. (1996). Aan autisme verwante stoornissen. Kind en Adolescent, 17, 157-158.

van Wieren, S., Schoemaker, C., \& van Balkom, A. J. L. M. (2007). Welke zorg gebruiken patiënten en wat zijn de kosten? In: Volksgezondheid Toekomst Verkenning, Nationaal Kompas Volksgezondheid. Bilthoven: RIVM. Retrieved 2007 from http://www.rivm.nl.

Verhulst, F. C., \& van der Ende, J. (1997). Factors associated with child mental health service use in the community. Journal of the American Academy for Child and Adolescent Psychiatry, 36, 901-909.

Verhulst, F. C., Van der Ende, J., Ferdinand, R. F., \& Kasius, M. C. (1997). The prevalence of DSM-III-R diagnoses in a national sample of Dutch adolescents. Archives of General Psychiatry, 54, 329-336.

World Health Organization (WHO) (1977). International classification of diseases, injuries and causes of death, 9th revision. Geneve: WHO. 